\title{
A LOGÍSTICA REVERSA CONTRIBUINDO PARA A MITIGAÇÃO DOS IMPACTOS AMBIENTAIS: UM ESTUDO DE CASO
}

\author{
https://dx.doi.org/10.48097/2674-8673.2021n5p13
}

\author{
Aline Gabrielle da Silva ${ }^{1}$ \\ Claudenize Silva Soares ${ }^{2}$ \\ Elias Meireles de Brito ${ }^{3}$ \\ Leticia Andrade da Silva ${ }^{4}$ \\ Susimary Leitão ${ }^{5}$
}

\section{RESUMO}

O presente artigo tem como objetivo apresentar os benefícios econômicos e ambientais obtidos com a implantação da Logística Reversa no grupo Meta 55 / Net Distribuidora. Para tanto, de forma exploratória, conduziu-se um estudo de caso, escolhendo como objetivo de análise o Centro de Distribuição da Meta 55. Foi realizada uma visita técnica guiada e entrevista aberta com os responsáveis pelo setor logístico da empresa. Verificou-se comparativamente a leitura existente e a realidade de sua aplicação na empresa. Ao final, apesar de não permitir conclusivamente pela natureza da pesquisa, foi possível identificar, mesmo assim, que o processo de logística reversa é resultado do comprometimento da empresa com seus ambientes interno e externo. Este artigo enumerou algumas razões para a empresa adotar esta prática de Logística Reversa, sendo uma fonte de vantagem competitiva para uma estratégia empresarial, chegando, assim, a obter redução de custos, de espaço e tempo em suas atividades.

Palavras-chave: Logística reversa. Fraldas descartáveis. Impactos ambientais.

Data de submissão: 19/04/2021

Data de aprovação: 21/05/2021

\begin{abstract} Center for Goal 55 as an analysis objective. A guided technical visit and an open interview with those responsible for the company's logistics sector was carried out. The existing reading

\footnotetext{
${ }^{1}$ Discente do Curso de Graduação Tecnológica em Logística da Faculdade Metropolitana.

E-mail: alinegabrielle@gmail.com

2 Discente do Curso de Graduação Tecnológica em Logística da Faculdade Metropolitana.

E-mail: nizepernambucana@hotmail.com

${ }^{3}$ Discente do Curso de Graduação Tecnológica em Logística da Faculdade Metropolitana.

E-mail: eliasmeireles1010@gmail.com

${ }^{4}$ Discente do Curso de Graduação Tecnológica em Logística da Faculdade Metropolitana.

E-mail: lety 15 a@hotmail.com

${ }^{5}$ Docente orientadora do Curso de Graduação Tecnológica em Logística da FMGR.

E-mail: susimary@gmail.com
}

This article aims to present the economic and environmental benefits obtained with the implementation of Reverse Logistics in the group Meta 55 / Net Distribuidora. For this purpose, in an exploratory way, a case study was conducted, choosing the goal of Distribution and the reality of its application in the company were verified comparatively. In the end, despite not allowing conclusively due to the nature of the research, it was still possible to 
identify that the reverse logistics process is the result of the company's commitment to its internal and external environments. This article enumerated some reasons for the company to adopt this practice of Reverse Logistics, being a source of competitive advantage for a business strategy, reaching, thus, obtaining a reduction in costs, space and time in its activities.

Keywords: Reverse logistics. Disposable diapers. Environmental impacts.

\section{INTRODUÇÃO}

A crescente demanda populacional ocorrida nas últimas décadas traz à tona a crescente problemática do lixo. Segundo dados da última edição do estudo Panorama dos Resíduos Sólidos no Brasil, são gerados anualmente 72,50 milhões de toneladas. Dessas, cerca de 42,6 milhões de toneladas são de resíduos sólidos urbanos. 58,7\% do material coletado seguiu para aterros sanitários, enquanto 29,90 milhões de toneladas de resíduos foram direcionados para locais inadequados como lixões que não possuem sistemas necessários para a proteção do meio ambiente. (ABRELPE, 2011).

A logística reversa faz com que o produto, parte ou resíduos voltem para a origem onde foi produzido para que possa ser reutilizado na produção de novos produtos ou agregados, favorecendo a preservação do meio ambiente, pois o material que seria descartado em lixões, aterros sanitários ou em locais de descarte ilegal volta ao ciclo produtivo para ser reaproveitado.

O tema sobre logística reversa, apesar da sua importância, ainda não possui uma literatura tão ampla quanto o gerenciamento do fluxo tradicional de matérias (da matériaprima ao cliente final consumidor).

Diante disso, a META 55 / NET DISTRIBUIDORA, sendo um grupo brasileiro dedicado à comercialização de produtos higiênicos e de consumo, principalmente na linha infantil, vive a presente preocupação com a reciclagem e com seu retorno ao destino correto.

O presente trabalho tem como foco a análise da destinação dos resíduos (papel, plástico, papelão) que são gerados na empresa, concentrando no modo como ele é feito e, principalmente, no motivo pelo qual o programa é desenvolvido. Será analisado até que ponto a empresa faz a destinação dos resíduos por obrigações legais ou por determinação da sua política interna.

Dentro do ambiente organizacional, a logística exige, por si só, a necessidade de as empresas obterem uma estratégia que seja bastante ligada aos "3R" (reduzir, reciclar e reutilizar), uma vez que a mesma é uma ferramenta voltada para a ecologia e que tem como 
intuito o reaproveitamento dos recursos adventos do consumo do último setor da cadeia de suprimentos, que são os clientes finais.

A logística reversa foi estabelecida com o objetivo de atender às necessidades de recolhimento de materiais devido ao pós-consumo e pós-venda. Com isso, pode-se afirmar que essa área da logística empresarial é a responsável por controlar o fluxo reverso dos materiais, após eles concluírem os seus ciclos de vidas úteis, na qual são agregados valores financeiros e sustentáveis, a lém de transmitir uma imagem corporativa legal para empresa.

No mesmo ponto, é possível perceber na Lei n. 12.305 a Política Nacional de Resíduos Sólidos, de 2 de agosto de 2010, que define como resíduos sólidos os materiais, substâncias, objetos ou bens descartados, resultante de atividades humanas ou empresariais, em sociedade, cuja destinação final se procede ou deve proceder nos estados sólido ou semissólido, ou ainda como gases contidos em recipientes, e líquidos cujas particularidades tornem inviável o seu lançamento na rede pública de esgotos ou em corpos d'agua. Por isso exigem soluções técnicas ou economicamente viáveis em face da melhor tecnologia disponível.

Sendo assim, empresas geradoras de resíduos são responsáveis pela destinação final dos mesmos. Cientes disso, as organizações devem providenciar estratégias voltadas à administração de seus bens após o consumo. Dessa forma, é importante ressaltar que a logística reversa, também conhecida como logística inversa, é de suma importância para as empresas, devido a sua fundamental função ao meio ambiente, à economia da empresa, e à imagem que a mesma passa aos seus clientes e demais colaboradores.

\section{LOGÍSTICA REVERSA}

De acordo com o Council of Supply Chain Management Professionals (CSCMP, 2010), a logística reversa é um segmento especializado que dá ênfase à movimentação e gestão dos produtos e recursos após a venda e a entrega ao cliente, incluindo a devolução para reparação e/ou crédito.

Segundo Stock (1998), a logística reversa se concentra no retorno de produtos, substituição de materiais e também o seu reaproveitamento, a reciclagem aplicada a determinados materiais, dentre outros.

Rogers e Tibben-Lembke (1999) tratam a logística reversa como um processo de planejamento, implementação e controle dos fluxos de matéria-prima, desde a sua origem até o ponto de consumo. Neste caso, o consumidor final. O objetivo é recuperar o valor gasto no produto através do descarte correto dos resíduos originados pelo produto em questão. 
Dentro desses aspectos, trazemos a tabela a seguir com alguns conceitos e/ou abordagens que foram transformados, agregando valor ao decorrer do tempo, alguns já demonstrados neste capítulo sobre logística reversa e que contribuíram para a formação do conceito atualmente mais utilizado:

Tabela 1 - Conceitos e abordagens sobre logística reversa

\begin{tabular}{|l|l|}
\hline Autor & Conceito \\
\hline $\begin{array}{l}\text { C. L. M. (1993, p. } \\
\text { 323) }\end{array}$ & $\begin{array}{l}\text { "Logística reversa é um termo relacionado às atividades envolvidas no } \\
\text { gerenciamento da movimentação e disposição de embalagens e } \\
\text { resíduos". }\end{array}$ \\
\hline Stock (1998, p. 20) & $\begin{array}{l}\text { "Logística reversa: refere-se ao papel da logística no retorno de } \\
\text { produtos, redução na fonte, reciclagem, substituição de materiais, reuso } \\
\text { de materiais, disposição de resíduos, reforma, reparação e } \\
\text { remanufatura". }\end{array}$ \\
\hline $\begin{array}{l}\text { Rogers e Tibben- } \\
\text { Lember (1999, p. }\end{array}$ & $\begin{array}{l}\text { "Processo de planejamento, implementação e controle da eficiência e } \\
\text { custo efetivo de matérias-primas, estoques em processo, produtos } \\
\text { acabados e as informaçóes correspondentes do ponto de consumo para } \\
\text { o ponto de origem com o propósito de recapturar o valor ou destinar à } \\
\text { apropriada disposição". }\end{array}$ \\
\hline $\begin{array}{l}\text { Bowersox e Closs } \\
\text { (2001, p. 51-52) }\end{array}$ & $\begin{array}{l}\text { "[..] Trata-se de um dos objetivos operacionais da logística moderna, } \\
\text { referindo-se a sua extensão além do fluxo direto dos produtos e } \\
\text { materiais constituintes e à necessidade de considerar os fluxos reversos } \\
\text { de produtos em geral". }\end{array}$ \\
\hline
\end{tabular}

Fonte: adaptado de Pereira et al (2013)

Com o passar do tempo, estes conceitos foram sendo reformulados e assim alcançou uma definição que atualmente é a mais complexa e na qual se identifica realmente todos os objetivos da logística reversa que é o conceito formulado por Leite (2009):

Área da logística empresarial que planeja, opera e controla o fluxo e as informações logísticas correspondentes, do retorno dos bens de pós-venda e pós-consumo ao ciclo de negócios ou ao ciclo produtivo, por meio dos canais de distribuição reversos, agregando-lhes valor de diversas naturezas: econômico, ecológico, de imagem corporativa, entre outros. (LEITE, 2009, p. 17).

Segundo Pereira et al (2013), o conceito de logística reversa é definido como uma das áreas da logística empresarial, pois engloba o conceito de logística já tradicional no meio empresarial, dentro de um conjunto de operações e/ou ações interligadas com base na redução de matérias-primas primárias, chegando até o destino final correto dos seus produtos, materiais e embalagens, destinando-os ao seu reuso adequado e/ou produção de energia. Ainda de acordo com o autor, é observado que a logística reversa também é denominada como logística integral ou inversa. 
Rogers e Tibben-Lembke (1999) mostram que o processo logístico reverso, conforme a figura 1, é de grande importância para as organizações, sejam elas agroindustriais, comerciais ou de serviços.

A lei $\mathrm{n}^{\mathrm{o}} 12.305$ de 2/08/2010 define a logística reversa como um instrumento de desenvolvimento econômico e social caracterizado por um conjunto de ações, procedimentos e meios destinados a viabilizar a coleta e a restituição dos resíduos sólidos ao setor empresarial, para reaproveitamento, em seu ciclo ou em outros ciclos produtivos, ou outra destinação final ambientalmente adequada.

Figura 1 - Processo Logístico Reverso

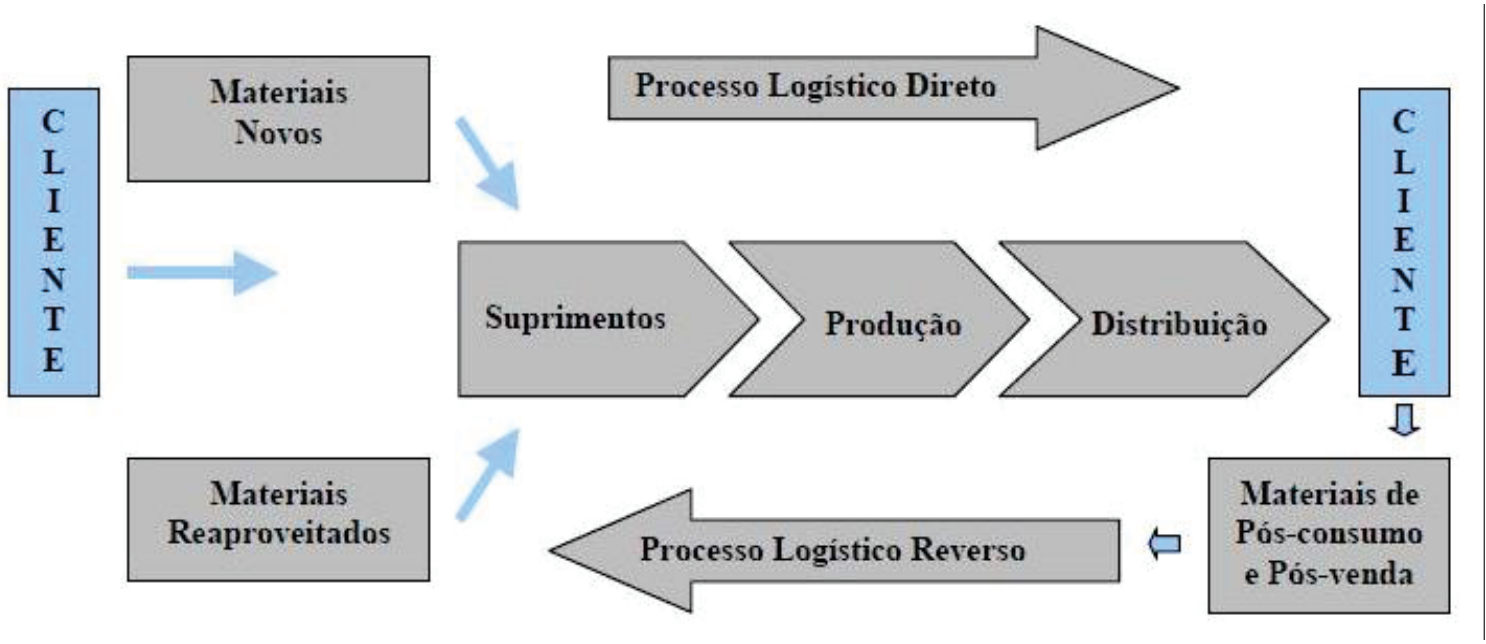

Fonte: adaptado de Rogers \& Tibben-Lembke (1999)

Um conceito geral para explicar a logística reversa é que os produtos consumidos e/ou não utilizados retornam por meio de canais de distribuição, conforme representado na Figura 1. Para Rogers e Tibben-Lembke (1999), assim como nos processos logísticos diretos, o processo logístico reverso faz o planejamento, implementa e controla o fluxo inverso ao fluxo produtivo direto, procurando agregar valor a esses produtos, reintegrando-os ao processo produtivo e de negócios.

\section{Fraldas descartáveis}

As fraldas de pano fizeram parte da vida de muita gente durante muitos anos. Por volta da década de 1980 as fraldas descartáveis passaram a ser mais acessíveis e a atingir um número maior de pessoas. Nas últimas décadas, a praticidade da fralda descartável (infantil e geriátrica) fez com que ela se tornasse essencial na vida da maioria das famílias. O produto, entretanto, passou a gerar discussões sobre seus perigos e impactos ambientais da fabricação 
ao descarte, e começou-se a falar sobre o renascimento das fraldas de pano e nas mais novas opções, que são as fraldas híbridas e as fraldas descartáveis biodegradáveis.

A fabricação de fraldas descartáveis consome muitos recursos e, depois de usadas, elas demoram anos para se decompor. Elas são constituídas por uma proporção significativa de matéria orgânica, além de plástico, fibras e polímero superabsorvente (Super Absorbent Polymer - SAP), tendo grande potencial para reciclagem e podendo ser reutilizado como matéria prima de outros produtos, evitando sua deposição em aterros sanitários ou incinerados (COLÓN et al., 2011; ESPINOSA et al., 2014).

A composição das fraldas descartáveis varia em termos de materiais utilizados e fabricantes (COLÓN et al., 2011). No entanto, Dey et al. (2016), apontam que a estrutura básica de uma fralda descartável consiste em quatro camadas principais.

Figura 2-Estrutura básica e materiais utilizados na fabricação das fraldas descartáveis

Camada Superior

(Polipropileno)

Camada de Aquisição

(Polpa de Celulose, Poliéster)

Camada Absorvente

(Polímero Superabsorvente)

Camada Inferior

(Polipropileno, Polietileno)

Fonte: adaptado de Dey et al. (2016)

A camada superior fica em contato direto com a pele do usuário, sendo composta por polipropileno macio e poroso, desenvolvido para transferir a urina e outros líquidos rapidamente para as camadas inferiores. Essa camada também pode conter loção que ajuda a proteger a pele, evitando desidratação e irritação. A composição de uma fralda descartável pode ser de aproximadamente $43 \%$ de polpa de celulose (celulose $f u f f$ ), $27 \%$ de polímero superabsorvente (PSA), 10\% de polipropileno (PP), 13\% de polietileno (PE), e 7\% de fitas, elásticos e adesivos. Tendo para isso, em sua fabricação, a utilização de recursos como árvores, petróleo, água e produtos químicos.

A camada de aquisição é composta de celulose modificada e poliéster, tendo a função de facilitar a movimentação do líquido para longe da pele, distribuindo-o uniformemente pelo núcleo da fralda. O núcleo da fralda corresponde à camada absorvente, constituída de gel de 
SAP, podendo estar misturado com celulose ou polímero poroso. A urina é bloqueada e armazenada dentro dessa camada. A camada inferior é a parte impermeável, tendo a função de impedir que o líquido escape para a pele. É tipicamente feita de polipropileno de textura macia, semelhante a um tecido, e laminada com uma película de polietileno.

Reciclar um produto é uma medida que agrega valor à marca e promove a preservação ambiental de grande impacto positivo, considerando as dificuldades impostas nesse processo. Especificamente a reciclagem de fraldas vem suprir um setor que tem dificuldades em encontrar uma empresa especializada neste tipo de procedimento.

A reciclagem de fraldas descartáveis é um procedimento ecologicamente correto em que as empresas ambientalmente responsáveis investem em uma destinação final sustentável. Para reciclar fraldas há duas etapas: separação da polpa e separação das sobras.

O primeiro passo é fazer a separação dos materiais, pois cada parte reciclável será enviada para um destino final diferente. Essa separação acontece por meio de uma empresa especializada em reciclagem de fraldas, onde é possível efetuar a separação do produto em máquina específica e apropriada.

\section{Separação da polpa}

Após a separação da polpa é realizada a reciclagem e envio para diversas empresas que utilizam esse material para fabricação de novos produtos, como a fabricação de tapetes higiênicos para linha "pet", além de ser emitido laudo conclusivo com detalhamento do processo.

\section{Separação das sobras}

As sobras são encaminhadas diretamente para as empresas de reciclagem especializadas neste tipo de material. Investir em reciclagem de fraldas é poupar o meio ambiente do contato prejudicial desse tipo de produto que pode levar mais de 500 anos para se decompor.

\section{Impacto Ambiental}

Considerando o contexto da logística reversa, não se pode deixar de citar a preocupação com o meio-ambiente, que é um dos principais fatores que a motivam. Segundo Lacerda (2002), a questão ambiental vem ganhando importância crescente desde a década de 70, quando os consumidores passaram a cobrar das indústrias de bens de consumo ou serviços 
maior consciência ambiental e só a partir da década de 90 é que sua influência se mostrou mais intensa.

Para Butter (2003), a relação da logística reversa com o meio ambiente tem importância porque as constantes movimentações de materiais residuais, provenientes dos processos de fabricação e das devoluções de produtos, poderão causar de alguma forma acidentes ambientais. Então, um sistema de gestão ambiental, quando implantado, fornece ferramentas e procedimentos que serão facilitadores na condução da logística reversa dos resíduos sólidos.

Para Donaire (1999), a questão ambiental nas empresas envolve: produtos obtidos de matéria-prima renováveis ou recicláveis, que não agridam o meio ambiente, e com baixo consumo de energia no processo; processos com poluição controlada, mínima geração de resíduos, nenhum risco para os trabalhadores, baixo consumo de energia e eficiência na utilização dos recursos; conscientização ambiental, com objetivo de ser mais competitivo; padrões ambientais, para gerar novas oportunidades; comprometimento gerencial; capacitação do pessoal, com treinamento em todos os níveis; capacidade da área de pesquisa e desenvolvimento de produtos ecologicamente corretos; e disponibilidade para investimentos em novas tecnologias.

Usualmente, ao se falar em meio ambiente, a definição mais amplamente difundida é um conceito simplista e reducionista desse termo, focando, principalmente, em fatos que ocorrem distantes da realidade, como desmatamentos, espécies em extinção, desertificação, dentre outros. Porém, é imprescindível que se trate o meio ambiente integralmente, e não somente parte dele. (PEREIRA, 2013).

Como define Coimbra (2002), o meio ambiente deve ser visto como um conjunto de elementos bióticos (flora e fauna) e abióticos (físicos e químicos), constituído por todos os ecossistemas, tanto sociais, culturais, econômicos e naturais, em que o ser humano se insere, social e individualmente, num processo de interação responsável com o meio, atendendo às necessidades de desenvolvimento das atividades humanas, à preservação dos recursos naturais e das características essenciais do entorno.

O termo impacto ambiental pode ser definido e aplicado em diversas áreas multidisciplinares, como no âmbito técnico, econômico e legal. A principal definição se dá no âmbito legal, conforme o artigo $1^{\circ}$ da Resolução CONAMA 01/86: 
ambiente, causada por qualquer forma de matéria ou energia resultante das atividades humanas que, direta ou indiretamente, afetam:

I - A saúde, a segurança e o bem-estar da população;

II - As atividades sociais e econômicas;

III - A biota;

IV - As condições estéticas e sanitárias do meio ambiente;

$\mathrm{V}$ - A qualidade dos recursos ambientais.

Segundo Torrejón e Safra (2015), o impacto ambiental pode ser definido como a diferença entre as condições ambientais que existem com a implementação de um projeto e essas condições sem o mesmo. Esta definição não tem um conteúdo técnico ou econômico, mas uma conotação ambiental que compara duas situações futuras hipotéticas, uma com a implementação do projeto e outra sem o mesmo.

\section{Figura 3 - Representação do conceito de impacto ambiental}

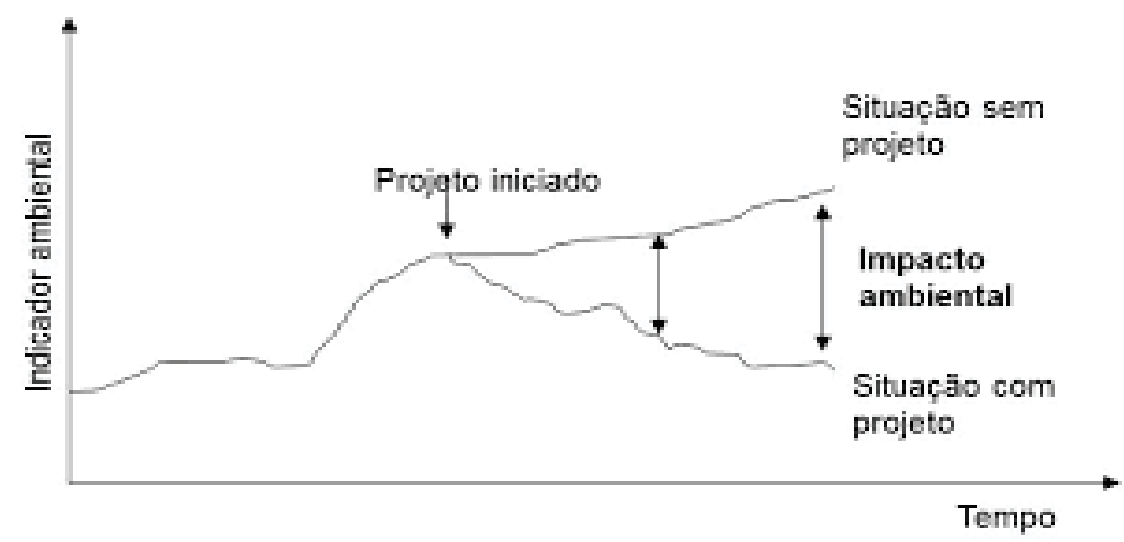

Fonte: Sánchez (2008)

Conforme a figura acima, o termo impacto ambiental refere-se às modificações feitas no ambiente, tanto positivas quanto negativas, ocorridas a partir da introdução de alguma atividade. Para medir esse impacto, deve-se analisar, a partir da observação de algum parâmetro (indicador ambiental), os efeitos no meio ambiente com a realização dessa ação e comparar com a situação futura do meio sem que houvesse essa perturbação.

No processo de avaliação de impacto ambiente (AIA), para simplificação, utiliza-se o conceito operacional de impacto ambiental, que consiste na utilização de indicadores ambientais para avaliar e comparar a diferença da provável situação futura com a situação presente. (SÁNCHEZ, 2008). Nesse contexto, insere-se o conceito de vulnerabilidade do meio, que tem sido usado para descrever a susceptibilidade dos sistemas físicos, biotipos e sociais (TORO et al., 2012).

O conceito de impacto ambiental significativo é aquele que será o foco no processo de AIA que está relacionado ao potencial que tem determinada atividade ou ação humana de causar alterações ambientais. Isso depende de dois fatores: as pressões impostas ao meio pela 
ação ou projeto, ou seja, a sobrecarga imposta ao ecossistema; e a vulnerabilidade do meio, ou seja, o inverso da resiliência, que por sua vez dependerá do estado de conservação do ambiente e das solicitações impostas anteriormente e cujos efeitos se acumularam; ou da importância do ambiente ou do ecossistema. (SÁNCHEZ, 2008). A Figura abaixo exemplifica o conceito de impacto ambiental significativo, relacionando -o com a necessidade do processo de avaliação de AIA para determinado empreendimento.

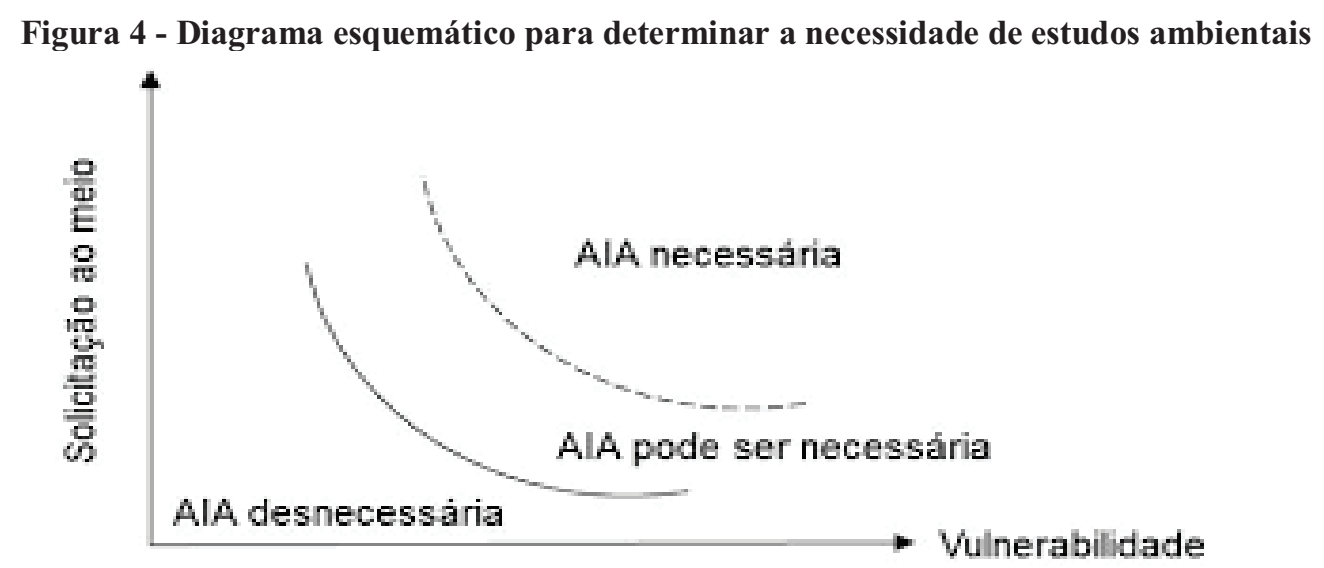

Fonte: Sanchez (2008)

Assim, o potencial de impacto ambiental resulta de uma combinação entre a pressão (característica inerente ao projeto e seus processos tecnológicos) e a vulnerabilidade do meio. (SÁNCHEZ, 2008). Empreendimentos que solicitem muito do meio e que estejam em áreas vulneráveis têm grandes chances de causarem impactos significativos e de necessitarem de AIA para sua implementação. Do mesmo modo, grande pressão de um meio não tão vulnerável também pode causar impactos significativos.

\section{Impactos Ambientais causados pelas Fraldas Descartáveis}

As fraldas descartáveis representam uma grande ameaça ao meio ambiente, pois de sua produção até seu descarte, o uso desse item tão comum já virou alvo de críticas. Para sua produção, além do uso de muita energia e água, é preciso plástico e papel, o que significa que a produção envolve a derrubada de árvores e o uso de um recurso não renovável: o petróleo. Estima-se que, nos três primeiros anos de vida, uma única criança seja responsável pelo uso de seis mil fraldas. Cada uma delas leva cerca de 450 anos para se decompor no meio ambiente.

Segundo dados da Associação Brasileira da Indústria de Higiene Pessoal, Perfumaria e Cosméticos (ABIHPEC), foram 5,6 bilhões de fraldas vendidas ao consumidor no mercado 
brasileiro no ano de 2009 e 7,9 bilhões no ano de 2014. Tendo em vista o ciclo de vida das fraldas descartáveis, além da sua persistência no meio ambiente pós-uso, o produto tem diferentes impactos relacionados a sua produção. Esse ciclo pode ser dividido nas seguintes fases:

- Extração da matéria-prima;

- Fabricação dos materiais;

- Manufatura do produto;

- Disposição final.

Quando descartada no meio ambiente, a parte da fralda composta por celulose pode se decompor em alguns meses, porém os polímeros superabsorventes e os componentes de plástico não podem, o que resulta na persistência desses resíduos no meio ambiente por longos períodos de tempo, possibilitando, quando dispostos em lixões (a céu aberto e sem preparação anterior do solo), a atração de insetos vetores de doenças e a contaminação das águas subterrâneas por micro-organismos presentes nas fezes que foram descartadas com as fraldas.

\section{METODOLOGIA}

O Procedimento inicial escolhido para nortear o presente trabalho foi a pesquisa bibliográfica. Em seguida, foi escolhido como objeto de estudo de caso o processo de logística reversa em uma empresa do setor de comercialização de produtos higiênicos e de consumo em Jaboatão dos Guararapes-PE.

Após a definição do estudo de caso, na terceira etapa, foi estabelecida a realização de uma visita técnica guiada à unidade e uma entrevista aberta com os responsáveis pelo setor de compras.

\section{DESENVOLVIMENTO DA PESQUISA DE CAMPO}

O grupo Meta 55 Distribuidora entende que a Logística Reversa é fundamental para o comércio, pois essa prática significa retornar tudo o que não foi utilizado ao fabricante, liberando assim espaço na distribuidora, o que permite melhor utilização das áreas físicas da companhia.

Segundo relatado pela gestora logística, no período anterior à implementação da prática de logística reversa, existia um problema crônico e crítico a respeito do espaço físico dos armazéns, pois estes estavam sendo subutilizados, com a ocupação de posições 
importantes por avarias, produtos com giro de venda longo, subprodutos ou utensílios logísticos, como pallet, por exemplo.

A partir da identificação desse problema o corpo diretivo da Meta 55 debruçou-se sobre esse sintoma a fim de identificar quais ações deveriam ser tomadas para que a causa raiz fosse tratada e assim o mesmo problema não viesse a se repetir.

Um detalhe importante sobre a implementação da prática da logística reversa é que esta passou a exigir um tratamento diferente, pois o vai e vem de mercadorias, tendo em vista que por este local passava produtos impróprios para a venda, gerava dificuldade tanto para armazenar os demais produtos próprios para a venda como alocar mão de obra operando sem riscos.

Figura 5 - Expedição do centro de distribuição CD da Meta 55

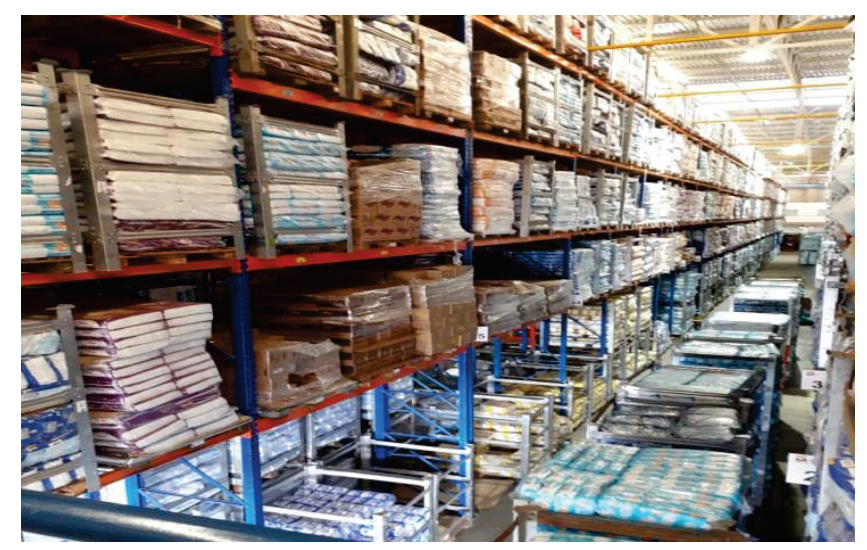

Fonte: Meta 55 Distribuidora

Conforme pode ser observado na foto da expedição do CD da empresa é possível identificar que já está subdimensionada, impossibilitando assim que quando o caminhão retornasse das lojas descarregasse todos os materiais que estavam sendo retornados.

Figura 6 - Doca de abastecimento CD Meta 55

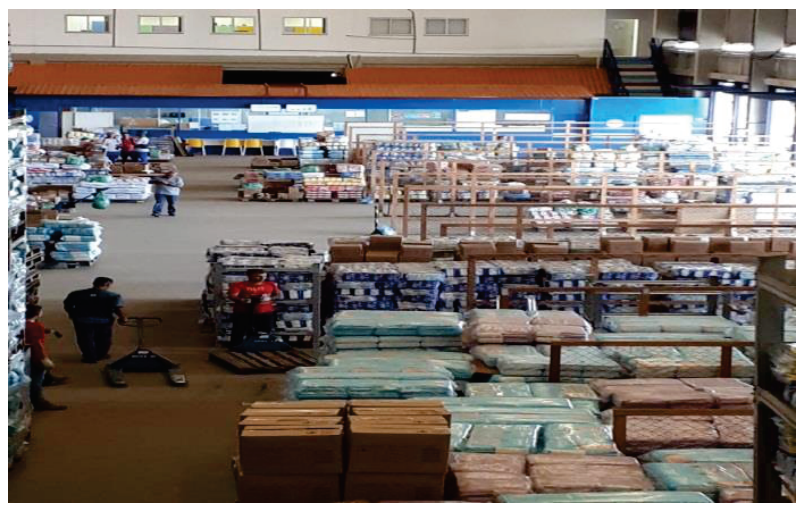

Fonte: Meta 55 distribuidora 
Na figura 6 podemos identificar, mais uma vez, a falta de espaço. Os caminhões já chegam vazios e prontos para o carregamento.

Figura 7 - Classificação da importância da logística reversa na empresa

61 respostas

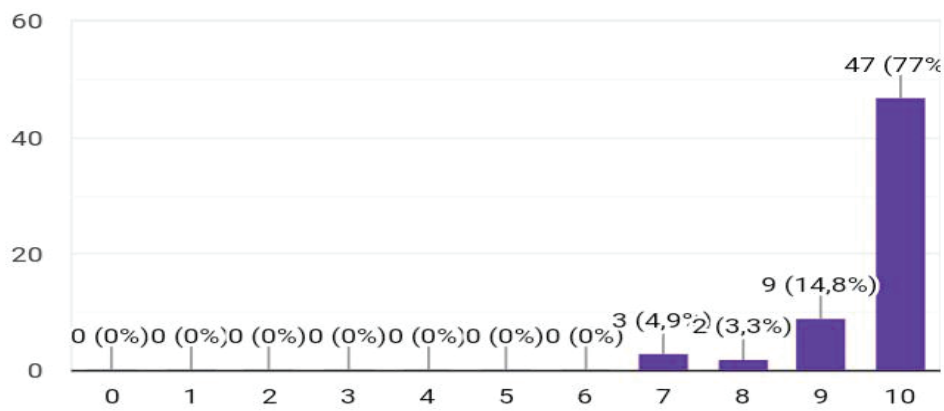

Fonte: Meta 55 Distribuidora

\section{Figura 8 - Colaboradores entrevistados}

61 respostas

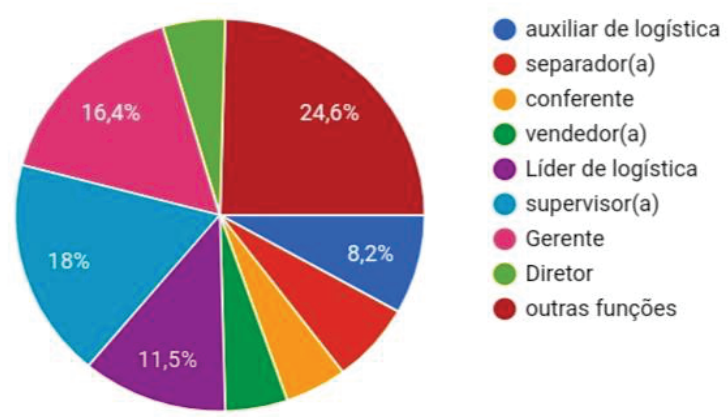

Fonte: Meta 55 Distribuidora

\section{CONSIDERAÇÕES FINAIS}

Este trabalho tinha como pergunta base: quando surgiu a ideia do uso da logística reversa na Meta 55 Distribuidora? Esta pergunta foi devidamente respondida através da visita técnica guiada realizada internamente na empresa pesquisada, levantamento de dados e geração de relatório.

Dessa forma, foi possível demonstrar a diferença do funcionamento que resultou no aumento de faturamento e gestão por logística reversa como uma ferramenta que traz ganhos ambientais à sociedade em geral. 
O objetivo geral do presente trabalho foi a verificação dos benefícios e ganhos econômicos e ambientais, obtidos com a aplicação da prática da logística reversa aplicada no processo de distribuição e armazenagem, no setor de comercialização de produtos higiênicos e consumo.

A empresa se mostrou com perfil inovador ao procurar implementar um modelo próprio de operação de sua logística reversa, também ressaltando o lado resiliente, pois apesar das dificuldades encontradas se manteve firme no objetivo até sua conclusão.

Importante salientar que a coragem e persistência da empresa foram essenciais para o sucesso da operação, visto que a falta de conhecimentos técnicos específicos naquele ramo foram substituídos pela intuição e responsabilidade com os negócios.

\section{REFERÊNCIAS}

ABRELPE. Panorama dos Resíduos Sólidos no Brasil. 2011. Disponível em: https://abrelpe.org.br/download-panorama-2011/. Acesso em: 15 maio 2020.

BUTTER, G. A. Desenvolvimento de um modelo de gerenciamento compartilhado dos resíduos industriais no sistema ambiental da empresa. 2003 f. Dissertação (Doutorado em Engenharia de Produção), Universidade de Santa Catarina, 2003.

COIMBRA, J. A. A. O outro lado do meio ambiente: uma incursão humanística na questão ambiental. Campinas: Millennium, 2002.

COLÓN, J. et al. Possibilities of composting disposable diapers with municipal solid wastes. Waste management \& research, [S.1.], v. 29, n. 3, p. 249-259, 2011.

COLÓN, J. et al. Performance of compostable baby used diapers in the composting process with the organic fraction of municipal solid waste. Waste management, Espanha, v. 33, n. 5, p. 1097-1103, 2013.

CONAMA - Conselho Nacional do Meio Ambiente. Resoluções do Conama: Resoluções vigentes publicadas entre setembro de 1984 e janeiro de 2012. MMA, Brasília, 2012.

CSCMP, Council of Supply Chain Management Professionals. Glossary of Terms. 2010. Disponível

https://cscmp.org/CSCMP/Educate/SCM_Definitions_and_Glossary_of_Terms.aspx. Acesso em: 08 jun. 2020.

DEY, S. et al. Exposure Factor considerations for safety evaluation of modern disposable diapers. Regulatory toxicology and pharmacology, [S.1], v. 81, p. 183-193, 2016.

DONAIRE, Denis. Gestão Ambiental na Empresa. São Paulo: Atlas, 1999. 
ESPINOSA, V, R. M. et al. Biological recycling of used baby diapers in a small-scale composting system. Resources, Conservation and recycling, [S.1.], v. 87, p. 153-157, 2014.

LACERDA, L. Logística reversa, uma visão sobre os conceitos básicos e as práticas operacionais. Centro de Estudos em Logística - COPPEAD - UFRJ - 2002.

LEITE, P. R. Logística Reversa: Meio Ambiente e Competitividade. 2. ed. São Paulo: Prentice Hall, 2009.

PEREIRA, André Luiz et al. Logística reversa e sustentabilidade. São Paulo: Cengage Learning, 2013.

PEREIRA, S. S.; CURI, R. C. Meio Ambiente, Impacto Ambiental e Desenvolvimento Sustentável: Conceituações Teóricas sobre o Despertar da Consciência Ambiental. REUNIR - Revista de Administração, Contabilidade e Sustentabilidade, v. 2, n.4, p.35-57, 2012.

ROGERS, D. S.; TIBBEN-LEMBKE, R. S. Indo para trás: tendências e práticas de logística reversa. Universidade de Nevada. Reno: CLM, 1998.

SANCHÉZ, Luiz Enrique. Avaliação de Impacto Ambiental: conceitos e métodos. São Paulo: Oficina de Textos, 2008. 495p.

STOCK, J. R. Desenvolvimento e Implementação de Programas de Logística Reversa. Estados Unidos da América: Conselho de Manejo Logística, 1998.

TORO, J.; DUARTE, O.; REQUENA, I.; ZAMORANO, M. Determining Vulnerability Importance in Environmental Impact Assessment. The case of Colombia. Environmental Impact Assessment Review, v. 32, n. 1, p. 107-117, 2012.

TORREJÓN, J. A.; SAFRA, P. C. El Impacto Ambiental Negativo y su Evaluación Antes, Durante y Después del Desarrollo de Actividades Productivas. Derecho \& Sociedad, v. 42, p. 223-233, 2015.

\section{APÊNDICE A - Roteiro de perguntas ao gestor}

1. Quando surgiu a ideia do uso da Logística Reversa na Meta 55 Distribuidora?

2. Por qual motivo a Meta Distribuidora optou por este método?

3. Qual a posição da Meta 55 Distribuidora em relação aos impactos ambientais? O que ela pensa para combatê-los?

4. Os funcionários da Meta 55 Distribuidora são instruídos sobre esse método de sustentabilidade? Se sim, de que forma?

5. Você, como Gestor(a) Logístico, encontrou algum ponto negativo ao usar a Logística Reversa na Meta 55 Distribuidora? Se sim, qual? 


\section{APÊNDICE B - Roteiro de perguntas aos colaboradores}

1. Sabendo que a logística reversa é uma ferramenta que tem como objetivo direcionar aquilo que seria desperdiçado para cooperativas e reciclagens, tornando assim o que seria lixo em algo aproveitável ou reutilizável, a empresa que você trabalha utiliza a logística reversa?

2. Qual a sua função na empresa?

3. Você, como funcionário da empresa, acredita ser importante o uso da logística reversa no combate aos impactos negativos ao meio ambiente?

4. Se você fosse gestor de uma empresa, usaria a logística reversa para proteger o meio ambiente?

5. Você acredita que seria importante as empresas utilizarem esse método como um meio sustentável? 